\title{
Salidroside downregulates microRNA-133a and inhibits endothelial cell apoptosis induced by oxidized low-density lipoprotein
}

\author{
YONGJIE ZHANG* , FEI LIN*, ZHIGANG YAN, ZHIGANG CHEN, \\ YINGEN CHEN, YILIN ZHAO and GUOAN ZHAO
}

The First Affiliated Hospital of Xinxiang Medical University, Henan Engineering Research Center for
Mitochondrion Biomedical of Heart, Heart Center, Xinxiang, Henan 453100, P.R. China

Received April 4, 2020; Accepted July 17, 2020

DOI: $10.3892 /$ ijmm.2020.4691

\begin{abstract}
Vascular endothelial cell apoptosis is regulated by microRNA-133a (miR-133a), which participates in the formation of atherosclerotic (AS) plaques, leading to the development of several cardiovascular diseases. Salidroside (SAL), the main component of Rhodiola, is considered to exert anti-AS effect; however, its mode of action remains unclear. Thus, the present study aimed to determine whether SAL inhibits endothelial cell apoptosis through the miR-133a pathway. Cultured human coronary artery endothelial cells (HCAECs) were exposed to oxidized low-density lipoprotein (ox-LDL). Cell viability and cytotoxicity were monitored by MTT assay. In parallel, the mRNA expression levels of miR-133a and Bcl-xL, and the protein levels of anti-apoptotic Bcl-xL and activated caspase-3 were measured. The apoptotic levels were examined by flow cytometry. Furthermore, the effects of silencing and overexpressing miR-133a on the parameters mentioned above were evaluated. Exposure to ox-LDL induced an increase in the expression of miR-133a, with a concomitant decrease in the level of Bcl-xL in the HCAECs; these effects were reversed by treatment with SAL. Importantly, the effects of SAL were impaired upon the silencing of miR-133a, whereas the overexpression of miR-133a partly restored the effects of SAL. On
\end{abstract}

Correspondence to: Professor Guoan Zhao, The First Affiliated Hospital of Xinxiang Medical University, Henan Engineering Research Center for Mitochondrion Biomedical of Heart, Heart Center, 88 Jiankang Road, Weihui, Xinxiang, Henan 453100, P.R. China

E-mail: guoanzhao@xxmu.edu.cn

Abbreviations: CHD, coronary heart disease; HCAECs, human coronary artery endothelial cells; $\mathrm{NC}$, negative control; OD, optical density; PBS, phosphate-buffered saline; PI, propidium iodide

*Contributed equally

Key words: salidroside, oxidized low-density lipoprotein, microRNA-133a, Bcl-xL, endothelial cell the whole, the findings of the present study demonstrate that SAL inhibits the ox-LDL-induced upregulation of miR-133a expression, while promoting the expression of $\mathrm{Bcl}-\mathrm{xL}$, thereby preventing endothelial cell apoptosis.

\section{Introduction}

Cardiovascular diseases, particularly coronary heart disease (CHD), have a high mortality rate worldwide (1). Atherosclerosis (AS) is the primary pathological basis of CHD. Endothelial function is considered to serve as an excellent benchmark of underlying vascular health, as it represents an orchestrated response to the numerous known and unknown processes that contribute to the development, progression and clinical presentation of AS (2). Oxidized low-density lipoprotein (ox-LDL) can induce endothelial cell apoptosis (3), which promotes the occurrence and development of AS. In this context, B-cell lymphoma extra-large (Bcl-xL) plays a pivotal role in mediating cellular apoptosis by maintaining the mitochondrial membrane potential and preventing the release of pro-apoptotic enzymes, such as caspases, from the mitochondria (4). Caspase-3 acts as a regulatory hub to control the onset of cellular apoptosis and plays a central role in activating further apoptotic enzymes. Therefore, preventing cellular apoptosis of the endothelial lining has become an attractive strategy for AS treatment, and drugs that effectively inhibit endothelial cell apoptosis are considered to have important clinical significance in future anti-AS therapies.

MicroRNAs (miRNAs or miRs) are single-stranded, short non-coding RNAs with an average length of 22-24 nucleotides that regulate gene expression by complementary base-pairing with their target mRNAs. Accumulating evidence indicates that miRNAs play an active role in the development of AS, participating in all steps, from initial plaque formation to plaque instability and rupture, and regulate endothelial and immune function (5). In particular, miRNA-133a has been proposed to play a central role in the development of CHD and AS plaque stability $(6,7)$. Several factors, including hyperglycemia, hyperlipidemia and hyperhomocysteinemia, increase the expression of miR-133a in endothelial cells, thereby promoting vascular endothelial dysfunction. Importantly, the 
inhibition of miR-133a targets the regulation of GTP cyclohydrolase-1 and protects vascular endothelial function to ultimately prevent AS (8). Despite its role in endothelial cell function, the role of miR-133a in the regulation of apoptosis remains unclear.

Salidroside (SAL; 2-4-hydroxyphenyl ethyl- $\beta$-Dglucopyranoside) is the main active component of the herb, Rhodiola, which has attracted substantial attention in recent years owing to its significant anti-AS effect $(9,10)$, particularly with respect to its effects on preserving endothelial cell function. SAL can protect the endothelium against oxidative stress, inflammation and endoplasmic reticulum stress; inhibit endothelial apoptosis; and delay endothelial senescence, consequently preventing the occurrence and development of AS (11). A recent study demonstrated that SAL promoted the expression of the anti-apoptotic protein, Bcl-xL, thereby inhibiting the induction of apoptosis mediated by $\mathrm{H}_{2} \mathrm{O}_{2}$ oxidative stress (12). Of note, miR-133a specifically regulates the expression of the Bcl-xL gene (13-15); however, it remains unclear as to whether SAL affects the miR-133a expression levels to, in turn, regulate the levels of anti-apoptotic proteins. Therefore, the aim of the present study was to explore the regulation of endothelial cell apoptosis by SAL through the miR-133a pathway and to provide reference data for further studies on the mechanisms of AS that could lead to the development of novel drug targets.

\section{Materials and methods}

Cells and cell culture. Cultured human coronary artery endothelial cells (HCAECs; ScienCell Research Laboratories, Inc.) were seeded in fibronectin-coated plates (BD Biosciences), and cultured in endothelial cell medium (ScienCell Research Laboratories, Inc.) supplemented with $5 \%$ fetal bovine serum and endothelial cell growth supplement (ECGS) The cells were maintained at $37^{\circ} \mathrm{C}$ in a humidified atmosphere with $5 \% \mathrm{CO}_{2}$. Cells from passages 4-7 were used in the experiments.

Cell treatment. HCAECs were seeded in 96-well plates and exposed to various concentrations of ox-LDL $(5,15,25,50$ and $75 \mu \mathrm{g} / \mathrm{ml}$; Beijing Solarbio Science \& Technology Co., Ltd.) and SAL $(0.5,1,5,10,50,100,500,1,000$ and $5,000 \mu \mathrm{M}$; Nanjing Zelang Biotechnology Co., Ltd.) for $12 \mathrm{~h}$ or $24 \mathrm{~h}$. HCAECs were also seeded in 6-well plates and exposed to 25,50 and $75 \mu \mathrm{g} / \mathrm{ml}$ ox-LDL for 12 and $24 \mathrm{~h}$. For each experiment, the cells were divided into 3 experimental groups: The control (untreated) group, ox-LDL-treated group and ox-LDL + SAL-treated group.

Detection of cell viability. Cells were seeded in 96-well plates for 12 and $24 \mathrm{~h}$, and $20 \mu \mathrm{l} /$ well of 3-[4,5-dimethylthiazol-2-yl]-2,5-diphenyl tetrazolium bromide (MTT; Beyotime Institute of Biotechnology, Inc.) were added to each well. The plates were incubated in a cell incubator at $37^{\circ} \mathrm{C}$ for $4 \mathrm{~h}$. Following incubation, the blue-purple crystals were dissolved in $150 \mu \mathrm{l}$ of dimethyl sulfoxide The optical density (OD) of the solution was read at $490 \mathrm{~nm}$, and cell viability was calculated according to the following formula: (OD value of treatment group-OD value of blank group)/(OD value of control group-OD value of blank group) $\mathrm{x} 100 \%$.
Lactate dehydrogenase $(L D H)$ release assay. To evaluate the cytotoxic effects of SAL on HCAECs, the level of extracellular LDH was measured using the LDH release test kit (Beyotime Institute of Biotechnology, Inc.) according to the manufacturer's recommendations. In brief, the cells were transferred to a 96-well plate and treated with various concentrations of SAL $(5,10,50,100,500$ and $10,000 \mu \mathrm{M})$ for 12 and $24 \mathrm{~h}$. The supernatants were harvested and centrifuged for $5 \mathrm{~min}$ at $400 \mathrm{x} \mathrm{g}$ in a porous plate centrifuge (centrifugation was carried out at room temperature). Subsequently, $120 \mu \mathrm{l}$ of the supernatant were mixed with $60 \mu \mathrm{l}$ of $\mathrm{LDH}$ detection solution in a new 96-well plate, incubated for $30 \mathrm{~min}$ at room temperature, and the absorbance at $490 \mathrm{~nm}$ was read on an enzyme-linked immunosorbent assay plate reader (Molecular Devices, LLC).

miRNA screening. Bioinformatics screening was performed using miRBase (http://www.mirbase.org) to confirm the miRNAs targeting the Bcl-xL gene. miRNA expression levels were detected by reverse transcription-quantitative polymerase chain reaction (RT-qPCR) after the HCAECs were exposed to ox-LDL for $24 \mathrm{~h}$, as described below.

Cell transfection. The cells were sub-cultured in a 6-well plate and grown to $60-70 \%$ confluency. The cells were then transfected with the miR-133a inhibitor (diluted in Opti-MEM) or miR-133a mimics, and their respective negative controls (NC; $10 \mu \mathrm{M}$ stock) (GenePharma) using Lipofectamine ${ }^{\circledR}$ RNAiMAX Reagent (Thermo Fisher Scientific, Inc.). Pre-mixed transfection reagents and RNA were mixed at a 1:1 ratio and incubated at room temperature for $5 \mathrm{~min}$ in a 6 -well plate. At $48 \mathrm{~h}$ following transfection, the cells were exposed to ox-LDL $(75 \mu \mathrm{g} / \mathrm{ml})$, and treated with SAL $(100 \mu \mathrm{M})$, or ox-LDL $(75 \mu \mathrm{g} / \mathrm{ml})+\mathrm{SAL}(100 \mu \mathrm{M})$ for $24 \mathrm{~h}$.

Detection of cell apoptosis. To determine cell apoptotic rates, the Annexin V-fluorescein isothiocyanate (FITC)/propidium iodide (PI) double staining kit (BD Biosciences) was used according to the manufacturer's instructions. In brief, the cells were detached from the culture flasks with $0.05 \%$ trypsin and washed twice with chilled phosphate-buffered saline (PBS). The cells were then resuspended in $100 \mu 1 \mathrm{X}$ binding buffer and stained with $5 \mu \mathrm{l}$ Annexin V-FITC, which stains apoptotic cells (early apoptotic Q2 and late apoptotic Q3 quadrant), and PI for $15 \mathrm{~min}$ at room temperature in the dark. The samples were analyzed using a flow cytometer (BD FACSCalibur, BD Biosciences) and the data were analyzed using FlowJo 7.6 software.

$R T$ - $q P C R$. Total RNA was extracted from the cells using phenol:chloroform. In brief, the cells were washed twice with chilled PBS, and RNAiso plus reagent (Takara Bio USA, Inc.) was used to lyse the cells for $10 \mathrm{~min}$ on ice. Following incubation, chloroform and isopropanol were added to the lysates, and the precipitate was washed with $75 \%$ ethanol. The final pellet was resuspended in DEPC water, and the concentration was measured using an ultramicro spectrophotometer to confirm that the A260/A280 ratio was between 1.8 and 2.0.

The expression levels of both miR-133a and Bcl-xL were measured using reverse transcription kit (638313 and RR047A, Takara Bio USA, Inc.) according to the manufacturer's 
recommendations and detected by quantitative PCR (miRNA and mRNA) with TB green staining. The relative expression was determined using the $2^{-\Delta \Delta C q}$ method (16), and the expression of U6 and GAPDH was used as internal control. The primers for miR-133a and Bcl-xL detection were synthesized by Shanghai Sangon Biotech. The primer sequences used for PCR were as follows: Bcl-xL forward, 5'-GCATATCAGAGC TTTGAACGG-3' and reverse, 5'-GAAGGAGAAAAAGGC CACAATG-3'; GAPDH forward, 5'-CATGAGAAGTATGAC AACAGCCT-3' and reverse, 5'-AGTCCTTCCACGATACCA AAGT-3'; miR-133a forward, 5'-GGCCTTTGGTCCCCT TCAA-3'; miR-133b forward, 5'-GTTTGGTCCCCTCAACCA GCTA-3'; let-7c-5p forward, 5'-GGGTGAGGTAGTAGGTTG T-3'; let-7g-5p forward, 5'-CCGGCTGAGGTAGTAGTTTGT ACAGTT-3; miR-491 forward, 5'-CTAGTGGGGAACCCT TCCATGAG-3'; miR-326 forward, 5'-ACCTCTGGGCCC TTCCTC-3'; and miR-608 forward, 5'-AGGGGTGGTGTT GGGACAGCTCCGT-3'. The post-primer and internal reference gene, U6, for miRNA were included in the Takara kit (cat. no. 638313); however, the company did not provide the sequences for confidentiality reasons. For Bcl-xL, according to the instructions of the kit, the RNA extracted from samples was incubated at $42^{\circ} \mathrm{C}$ for $5 \mathrm{~min}, 37^{\circ} \mathrm{C}$ for $15 \mathrm{~min}$, and $85^{\circ} \mathrm{C}$ for $5 \mathrm{sec}$ for reverse transcription. PCR amplification was carried out using a two-step method; the first step involved pre-denaturation for $30 \mathrm{sec}$ at $95^{\circ} \mathrm{C}$, and the second step involved 40 cycles of amplification. The reaction conditions were $95^{\circ} \mathrm{C}$ for $5 \mathrm{sec}$ followed by $60^{\circ} \mathrm{C}$ for $34 \mathrm{sec}$. For miRNA reverse transcription, the extracted RNA was incubated at $37^{\circ} \mathrm{C}$ for $1 \mathrm{~h}$, followed by $85^{\circ} \mathrm{C}$ for $5 \mathrm{~min}$. PCR amplification was carried out using a two-step method; the first step involved pre-denaturation for $10 \mathrm{sec}$ at $95^{\circ} \mathrm{C}$, and the second step involved 40 cycles of amplification. The reaction conditions were $95^{\circ} \mathrm{C}$ for $5 \mathrm{sec}$ followed by $60^{\circ} \mathrm{C}$ for $20 \mathrm{sec}$.

Western blot analysis. The cells were collected in chilled RIPA lysis buffer (Beyotime Institute of Biotechnology, Inc.) containing protease inhibitor (PMSF and cocktail) to extract total proteins, and the protein concentration was detected using a BCA kit (Beyotime Institute of Biotechnology. Inc). Proteins ( 20 or $30 \mathrm{mg}$ ) were separated by 12 or $15 \%$ sodium dodecyl sulfate-polyacrylamide gel electrophoresis, and then transferred to polyvinylidene fluoride membranes. The membranes were then incubated with the following antibodies overnight at $4^{\circ} \mathrm{C}$ with rocking: Rabbit anti-Bcl-xL (1:2,000, cat. no. 2764T, Cell Signaling Technology, Inc.), rabbit anti-caspase-3 (1:500, cat. no. 9662 , Cell Signaling Technology, Inc.) and mouse anti- $\beta$-actin (1:2,000, cat. no. 60008-1-Ig, ProteinTech Group, Inc.). After washing, the membranes were incubated with the corresponding secondary antibodies (diluted 1:5,000, cat. no. 115-155-075 and 111-545-144, Jackson Laboratory) at room temperature for $1.5 \mathrm{~h}$. A chemiluminescence gel imaging analysis system was used to develop the image, and quantification was conducted using ImageJ software (https://imagej.nih.gov/ij/docs/index.html).

Statistical analysis. Each experiment was repeated at least 3 times. All data are presented as the means \pm standard deviation. All statistical analyses were conducted using SPSS 25.0 software (SPSS, Inc.), and data plotting was conducted in GraphPad Prism version 6. Differences between 2 groups

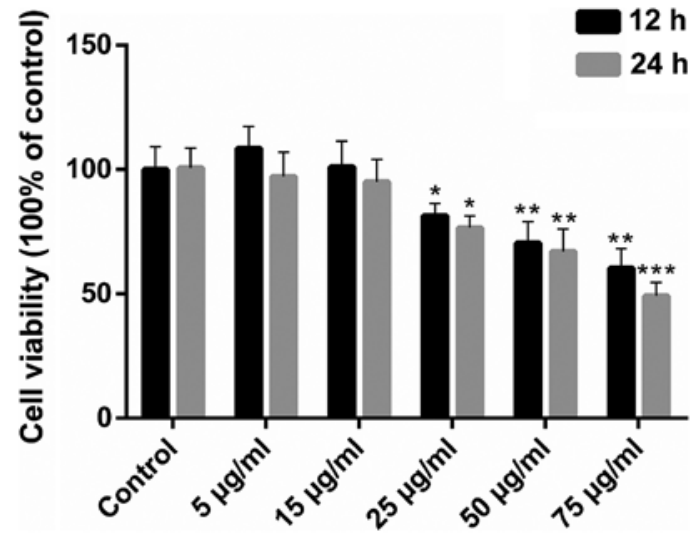

Figure 1. ox-LDL inhibits the activity of HCAECs. Results of MTT assay at 12 and $24 \mathrm{~h}$ of ox-LDL exposure to HCAECs are shown. ${ }^{*} \mathrm{P}<0.05,{ }^{* *} \mathrm{P}<0.01$, ${ }^{* * *} \mathrm{P}<0.001$ vs. control group. ox-LDL, oxidized low-density lipoprotein; HCAECs, human coronary artery endothelial cells.

were compared by unpaired t-tests, and differences among multiple groups were compared by one-way analysis of variance followed by Tukey's test as appropriate. Differences with $\mathrm{P}<0.05$ were considered statistically significant.

\section{Results}

$O x-L D L$ inhibits the viability of HCAECs. Exposure to ox-LDL impaired HCAEC viability only at concentrations $>25 \mu \mathrm{g} / \mathrm{ml}$ (Fig. 1; $\mathrm{P}<0.05$ ). When exposure to $75 \mu \mathrm{g} / \mathrm{ml}$ ox-LDL was prolonged for $24 \mathrm{~h}$, cell viability was inhibited more significantly $(\mathrm{P}<0.001)$. Therefore, 25,50 and $75 \mu \mathrm{g} / \mathrm{ml}$ were used as the screening concentrations for the model of ox-LDL-induced apoptosis.

ox-LDL downregulates Bcl-xL expression and activates caspase-3 to promote the apoptosis of HCAECs. ox-LDL-induced endothelial cell apoptosis is a widely used model in the study of the mechanisms of AS $(17,18)$. In the present study, flow cytometry revealed that compared to the untreated control group, apoptosis began to occur in the group exposed to $50 \mu \mathrm{g} / \mathrm{ml}$ ox-LDL for $12 \mathrm{~h}$, while the apoptotic rate increased in the group exposed to $25 \mu \mathrm{g} / \mathrm{ml}$ for $24 \mathrm{~h}$. In addition, the apoptotic level of the HCAECs was significantly increased at an concentration of $75 \mu \mathrm{g} / \mathrm{ml}$ (Fig. 2A and B).

The expression level of the anti-apoptotic protein, Bcl-xL, decreased gradually with the increasing ox-LDL concentration $(25-75 \mu \mathrm{g} / \mathrm{ml})$ and treatment duration (12 and $24 \mathrm{~h}$ ) (Fig. 2C and D).

The activation of caspase- 3 by cleavage is the final step in the induction of apoptosis. To confirm the induction of apoptosis, HCAECs were exposed to ox-LDL for 12 and $24 \mathrm{~h}$, and the level of cleaved caspase- 3 was determined. Similarly, the level of cleaved caspase- 3 increased at the concentration of $50 \mu \mathrm{g} / \mathrm{ml}$ in the group exposed to ox-LDL for $12 \mathrm{~h}$, and the activation of caspase-3 in the group exposed ox-LDL $(25 \mu \mathrm{g} / \mathrm{ml})$ for $24 \mathrm{~h}$, while the concentration of $75 \mu \mathrm{g} / \mathrm{ml}$ ox-LDL significantly increased the level of cleaved caspase-3 (Fig. 2E and F).

SAL protects the HCAECs from ox-LDL-induced apoptosis. SAL inhibited cell viability only at concentrations $>1,000 \mu \mathrm{M}$ 
A

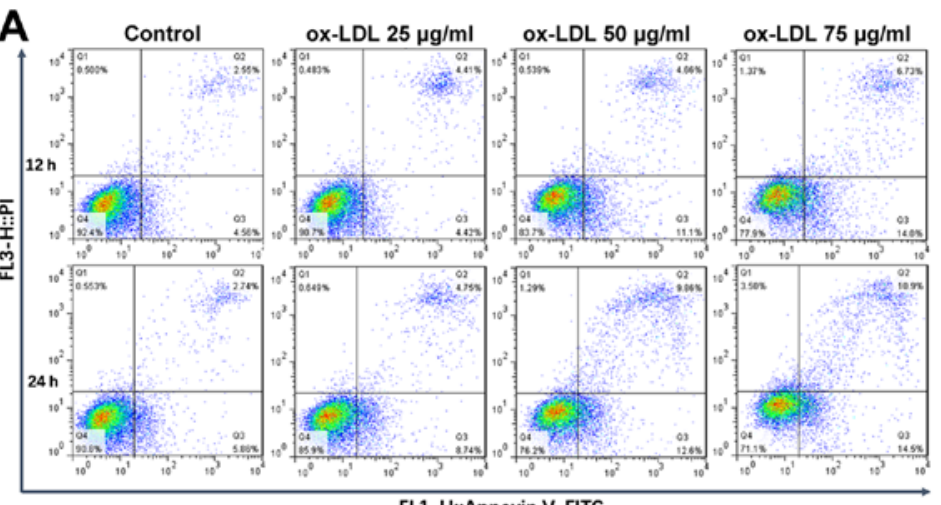

B

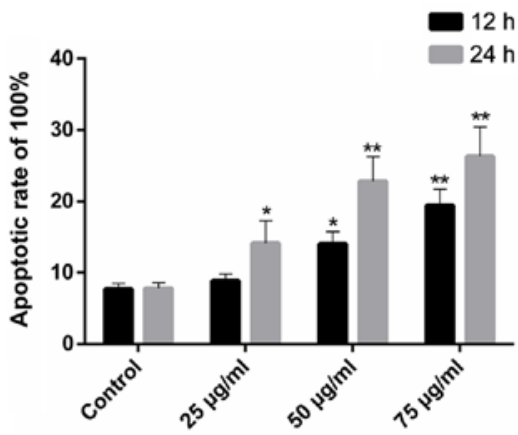

C

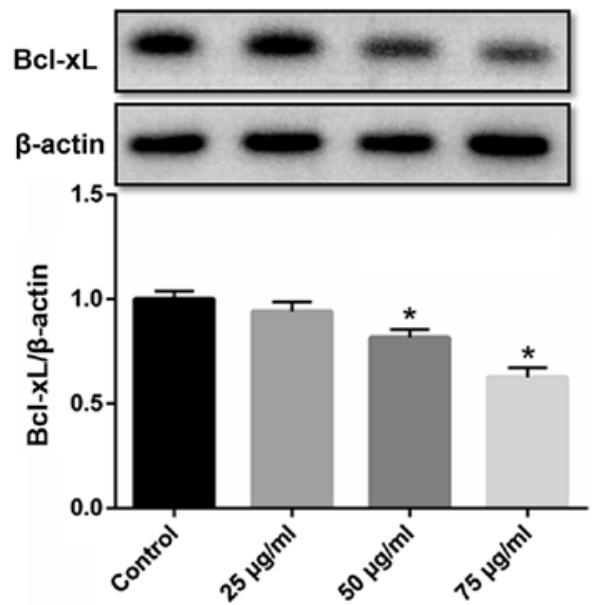

E cleaved

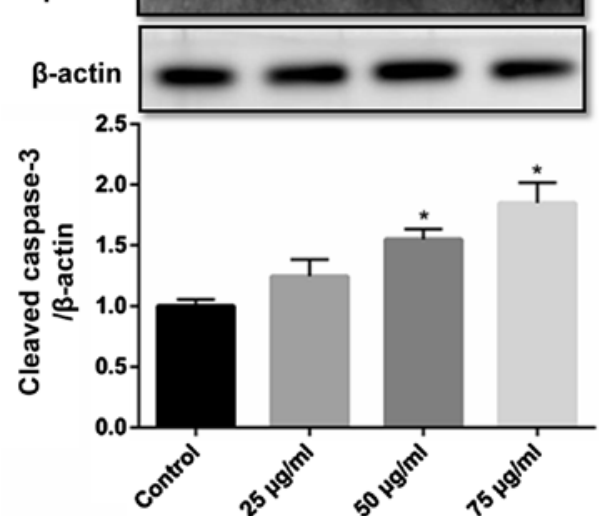

D
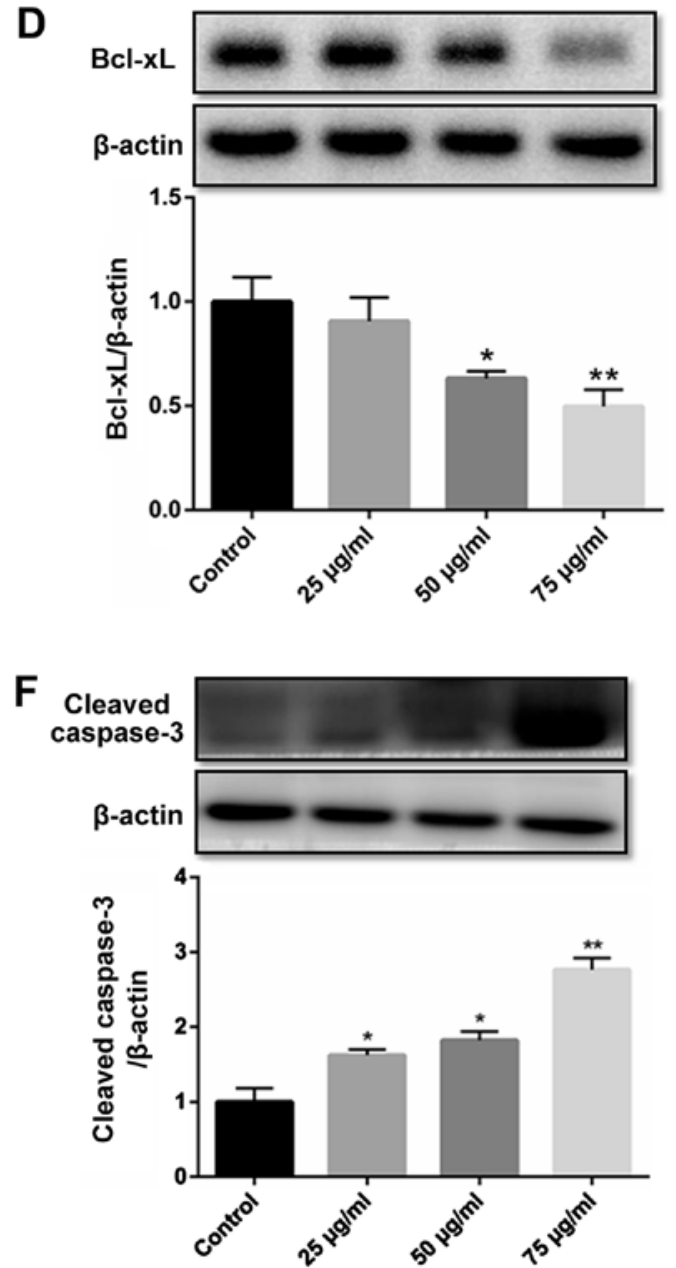

Figure 2. ox-LDL downregulates Bcl-xL expression and activates caspase- 3 to promote the apoptosis of HCAECs at different time points (12 and $24 \mathrm{~h}$ ). (A and B) Results of flow cytometry of HCAECs exposed to ox-LDL for 12 and $24 \mathrm{~h}$. (C and D) Bcl-xL expression in HCAECs exposed to ox-LDL for 12 and $24 \mathrm{~h}$, respectively. (E and F) ox-LDL induced the expression of cleaved caspase-3 in HCAECs following exposure for 12 and $24 \mathrm{~h}$, respectively. ${ }^{*} \mathrm{P}<0.05$, ${ }^{* *} \mathrm{P}<0.01$ vs. control group. ox-LDL, oxidized low-density lipoprotein; HCAECs, human coronary artery endothelial cells.

(Fig. 3A; P<0.05). Therefore, the low, medium and high concentrations of SAL at 10,50 and $100 \mu \mathrm{M}$, respectively were selected for use in further experiments.

In addition to the MTT assay, LDH release assay was used to evaluate the effects of ox-LDL and SAL on cell toxicity. An increase in the SAL concentration $(5-10,000 \mu \mathrm{M})$ did not affect the amount of LDH released (Fig. 3B). Taken together, these results indicated that SAL did not have any potential toxicity at 10,50 and $100 \mu \mathrm{M}$.
SAL prevented ox-LDL-mediated apoptosis in a concentration-dependent manner, with the concentrations $>10 \mu \mathrm{M}$ exerting the most potent anti-apoptotic effect (Fig. 3C and D). Following treatment with SAL, the expression of Bcl-xL was upregulated in a concentration-dependent manner (Fig. 3E). Importantly, SAL also reversed the increase in the cleaved caspase-3 levels in a concentration-dependent manner (Fig. 3F).

However, no significant increase or decrease in the mRNA level of Bcl-xL under ox-LDL induction was observed 
A

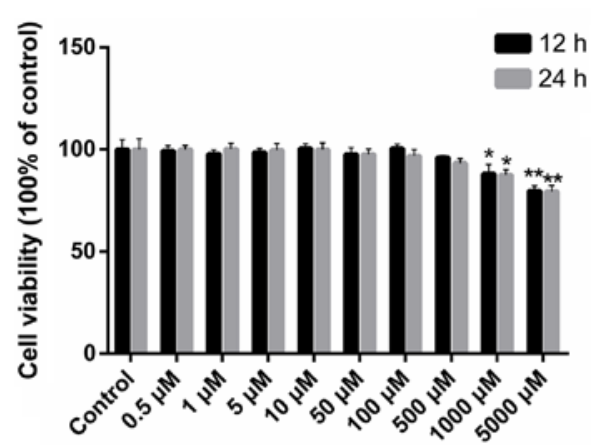

B

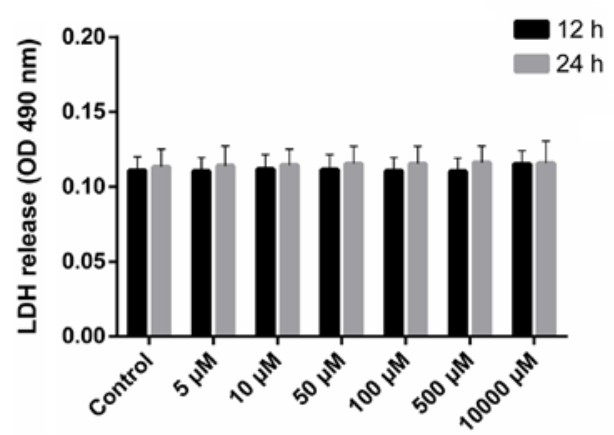

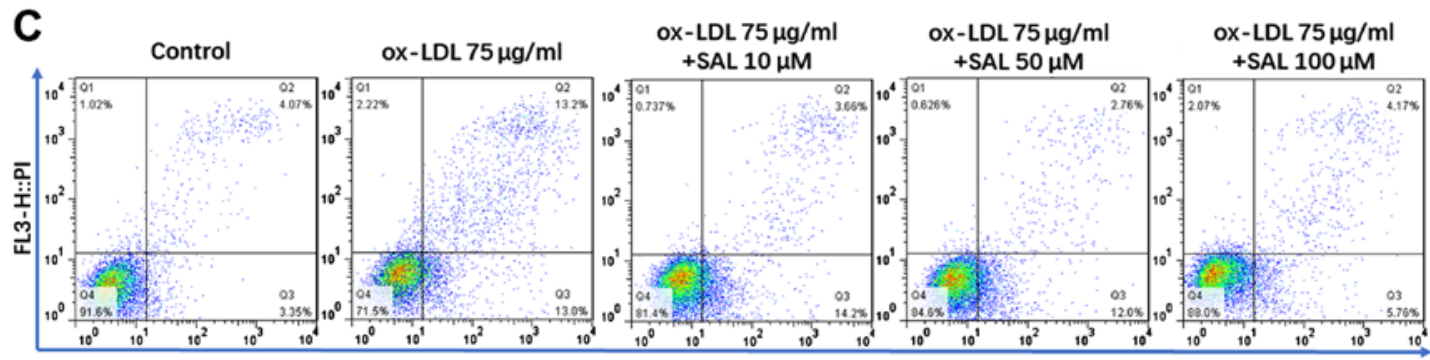

FL1-H::Annexin V-FITC

D

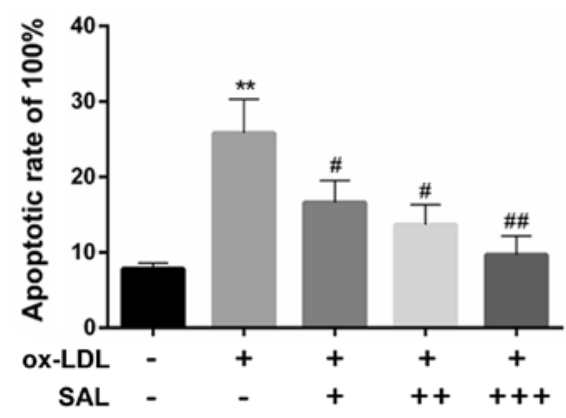

$\mathbf{F}$

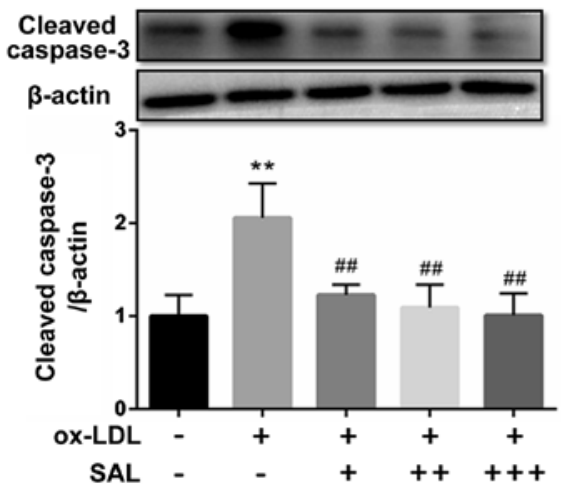

E

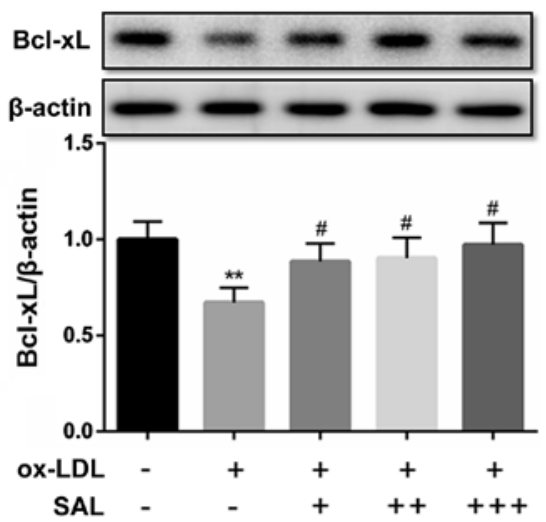

G

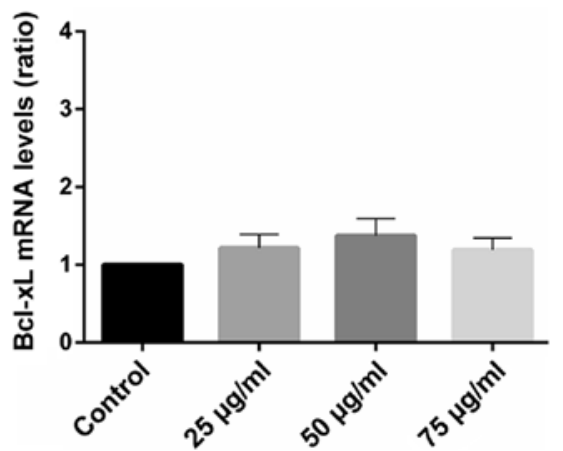

Figure 3. SAL protects HCAECs from apoptosis induced by ox-LDL. (A) Results of MTT assay of HCAECs treated with SAL for 12 and $24 \mathrm{~h}$. (B) Results of the LDH release assay in HCAECs treated with SAL for 12 and $24 \mathrm{~h}$. (C and D) SAL (24 h treatment) inhibits the ox-LDL-induced apoptosis of HCAECs cells as determined by flow cytometry. (E and F) SAL reverses the decrease in Bcl-xL expression and the increase in cleaved caspase-3 levels in HCAECs induced by ox-LDL for $24 \mathrm{~h}$. (G) mRNA levels of Bcl-xL in HCAECs exposed to ox-LDL with or without SAL co-treatment for $24 \mathrm{~h}$. " $\mathrm{P}<0.05$, " $\mathrm{P}<0.01$ vs. control; " $\mathrm{P}<0.05$, ${ }^{\# \#} \mathrm{P}<0.01$ treatment with ox-LDL alone vs. treatment with ox-LDL + SAL. -, without any drug treatment; $+10 \mu \mathrm{M},++50 \mu \mathrm{M},+++100 \mu \mathrm{M} \mathrm{SAL}+75 \mu \mathrm{g} / \mathrm{ml}$ ox-LDL. SAL, salidroside; ox-LDL, oxidized low-density lipoprotein; HCAECs, human coronary artery endothelial cells; LDH, lactate dehydrogenase.

(Fig. 3G). Since bioinformatics analyses predicted that miRNAs may regulate approximately one-third of all human genes $(19,20)$, in the present study, the related literature for the targeted regulation of Bcl-xL by miRNAs was screened as the starting point of the research.
Abnormal increase in miR-133a expression in apoptotic HCAECs is reversed by SAL. A literature search confirmed a total of 7 miRNAs [miR-133a (13), miR-133b (13), let-7c (21), let-7g (21), miR-491 (22), miR-326 (23) and miR-608 (24)] that target Bcl-xL transcripts. Among these, the expression level 

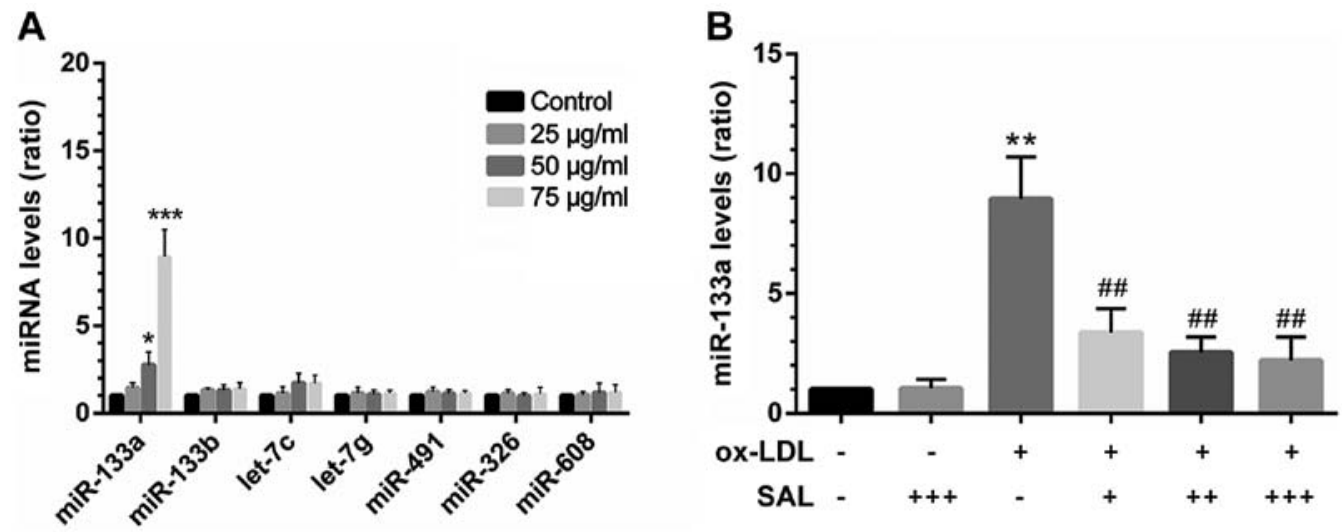

Figure 4. Abnormal increase in the miR-133a levels in the model of HCAEC apoptosis induced by ox-LDL is reversed by SAL. (A) At $24 \mathrm{~h}$ after HCAEC apoptosis was induced by various concentrations of ox-LDL, miRNAs targeting Bcl-xL were screened by RT-qPCR. (B) SAL reversed the increase in miR-133a levels in HCAECs exposed to ox-LDL $(24 \mathrm{~h}) .{ }^{*} \mathrm{P}<0.05,{ }^{* *} \mathrm{P}<0.01,{ }^{* * *} \mathrm{P}<0.001$ vs. control; ${ }^{\# \#} \mathrm{P}<0.01$ treatment with ox-LDL alone vs. treatment with ox-LDL+SAL, -, without any drug treatment; $+10 \mu \mathrm{M},++50 \mu \mathrm{M},+++100 \mu \mathrm{M} \mathrm{SAL}+75 \mu \mathrm{g} / \mathrm{ml}$ ox-LDL. SAL, salidroside; ox-LDL, oxidized low-density lipoprotein; HCAECs, human coronary artery endothelial cells.

of miR-133a was abnormally increased in ox-LDL-exposed cells (Fig. 4A). However, co-treatment with SAL impaired miR-133a overexpression under the induction of apoptosis (Fig. 4B). In addition, by searching the literature, it was found that Liu et al, Ji et al and Ma et al (13-15) used luciferase assay and target gene mutation to confirm that Bxl-xL was the target gene of miR-133a.

miR-133a participates in the ox-LDL-induced apoptosis of HCAECs. The expression level of miR-133a was confirmed to be increased following transfection with miR-133a mimics and decreased following transfection with miR-133a inhibitor to obtain miR-133a overexpression and silenced cell models, respectively (Fig. 5A).

Following the overexpression of miR-133a in ox-LDL-exposed cells, the cell apoptotic rates significantly increased compared to those of the untreated group, whereas no significant difference was observed following the knockdown of miR-133a (Fig. 5B and C). This suggested that endogenous miR-133a may not be directly involved in the process of apoptosis.

After miR-133a overexpression, Bcl-xL transcript levels significantly decreased (Fig. 5D), whereas there was no significant change in Bcl-xL transcript levels after knockdown of miR-133a (Fig. 5E). Treatment with SAL also reversed the pro-apoptotic effect (Fig. 5D). Following the addition of SAL, the mimics group exhibited an anti-apoptotic effect, whereas the miR-133a inhibitor did not affect apoptosis.

To further confirm that miR-133a is involved in the process of endothelial cell apoptosis, the protein expression of cleaved caspase-3 was further examined. No significant difference in the expression of cleaved caspase- 3 was observed after the silencing of miR-133a (Fig. 5F); however, the activation of caspase- 3 was significantly increased by the overexpression of miR-133a, and SAL decreased the activation of caspase-3 (Fig. 5G).

SAL reverses miR-133-induced apoptosis, and this effect is suppressed following the knockdown of miR-133a. The ox-LDL-induced apoptosis of HCAECs with miR-133a overexpression was reversed by treatment with SAL. However, this anti-apoptotic effect of SAL was attenuated following the knockdown of miR-133a (Fig. 6A and B). This finding suggested that SAL can inhibit endothelial cell apoptosis induced by ox-LDL by downregulating miR-133a.

Following the knockdown of miR-133a, the decrease in the Bcl-xL expression level induced by ox-LDL was not be reversed by SAL, whereas the anti-apoptotic effect of SAL was partly restored following the overexpression of miR-133a (Fig. 6C). Taken together, these results suggest that SAL can directly act on miR-133a to regulate the expression of Bcl-xL.

\section{Discussion}

The endothelium acts as a physiological barrier between the blood and blood vessels, and plays a central role in the development of AS. Endothelial cell apoptosis can increase the proliferation and migration of smooth muscle cells, promote blood coagulation and participate in the development of AS (25). The instability and rupture of plaques are closely related to endothelial cell apoptosis (26). The present study aimed to explore a novel approach and therapeutic target of salidroside against endothelial cell apoptosis.

In general terms, apoptosis is initiated by a signaling transduction cascade mediated by members of the $\mathrm{Bcl}-2$ protein family. Of these, the apoptosis-initiating protein, Bid, induces the release of cytochrome $c$ by binding and isolating the anti-apoptotic proteins Bcl-2 and Bcl-xL in the mitochondrial outer membrane (27). The increased cytochrome $c$ efflux can then drive multimolecular complexes to activate caspase- 3 and caspase-7 to initiate apoptotic cascades (28). Bcl-xL, encoded by the $B C L 2 L 1$ gene, is a major member of the $\mathrm{Bcl}-2$ protein family. Bcl-xL is superior to Bcl-2 and Mcl-1 in preventing DNA damage-induced apoptosis (29). The overexpression of Bcl-xL protects endothelial cells from apoptosis mediated by DNA damage agents and pro-inflammatory factors (30). Therefore, $\mathrm{Bcl}-\mathrm{xL}$ is more valuable to the study of apoptosis. The present study demonstrated that endothelial cells exposed to ox-LDL exhibit a decreased Bcl-xL level, caspase-3 activation and an increased apoptotic rate, which are related to 
A

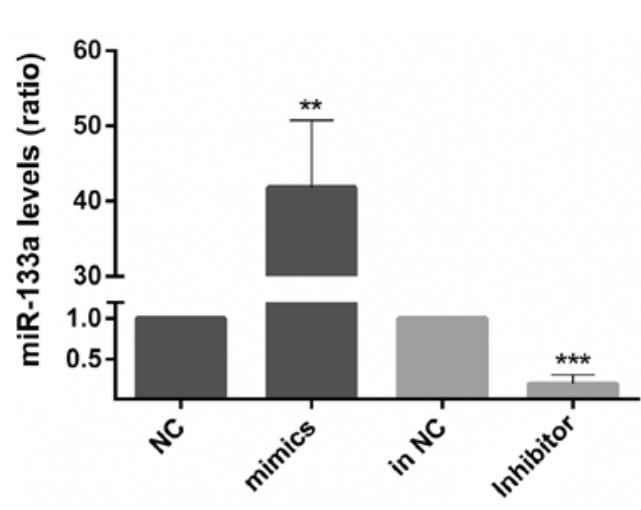

B

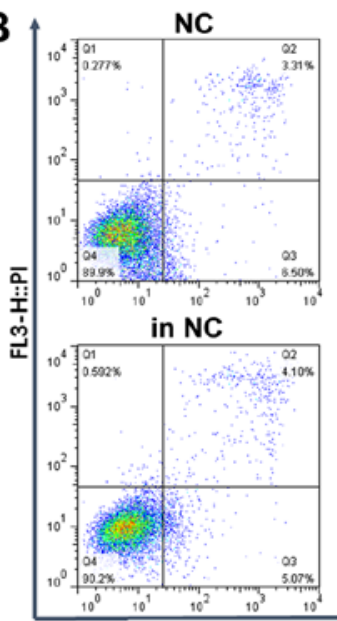

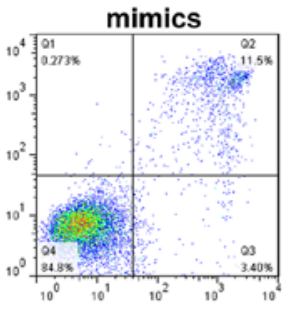

Inhibitor

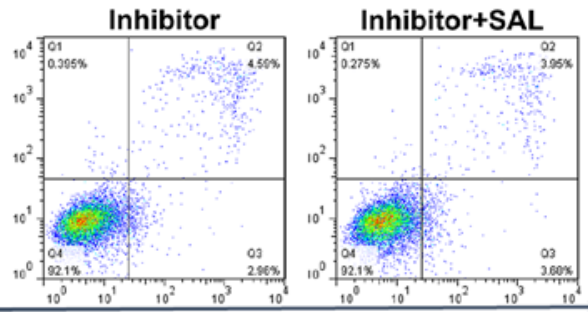

FL1-H::Annexin V-FITC

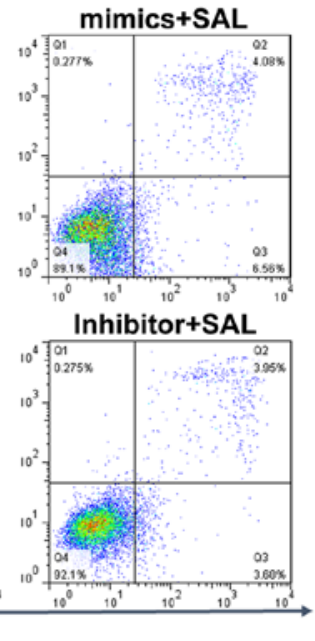

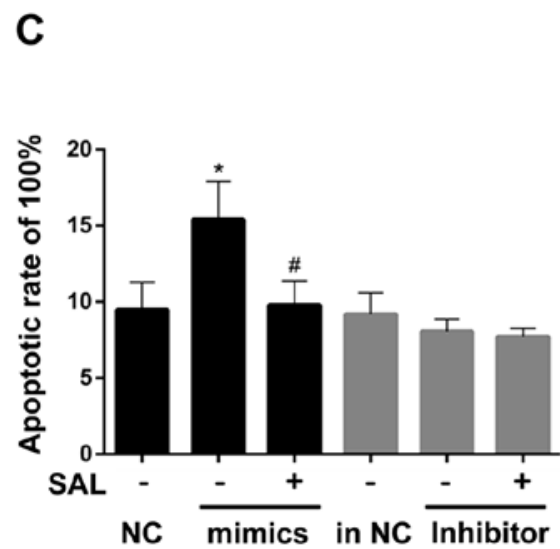
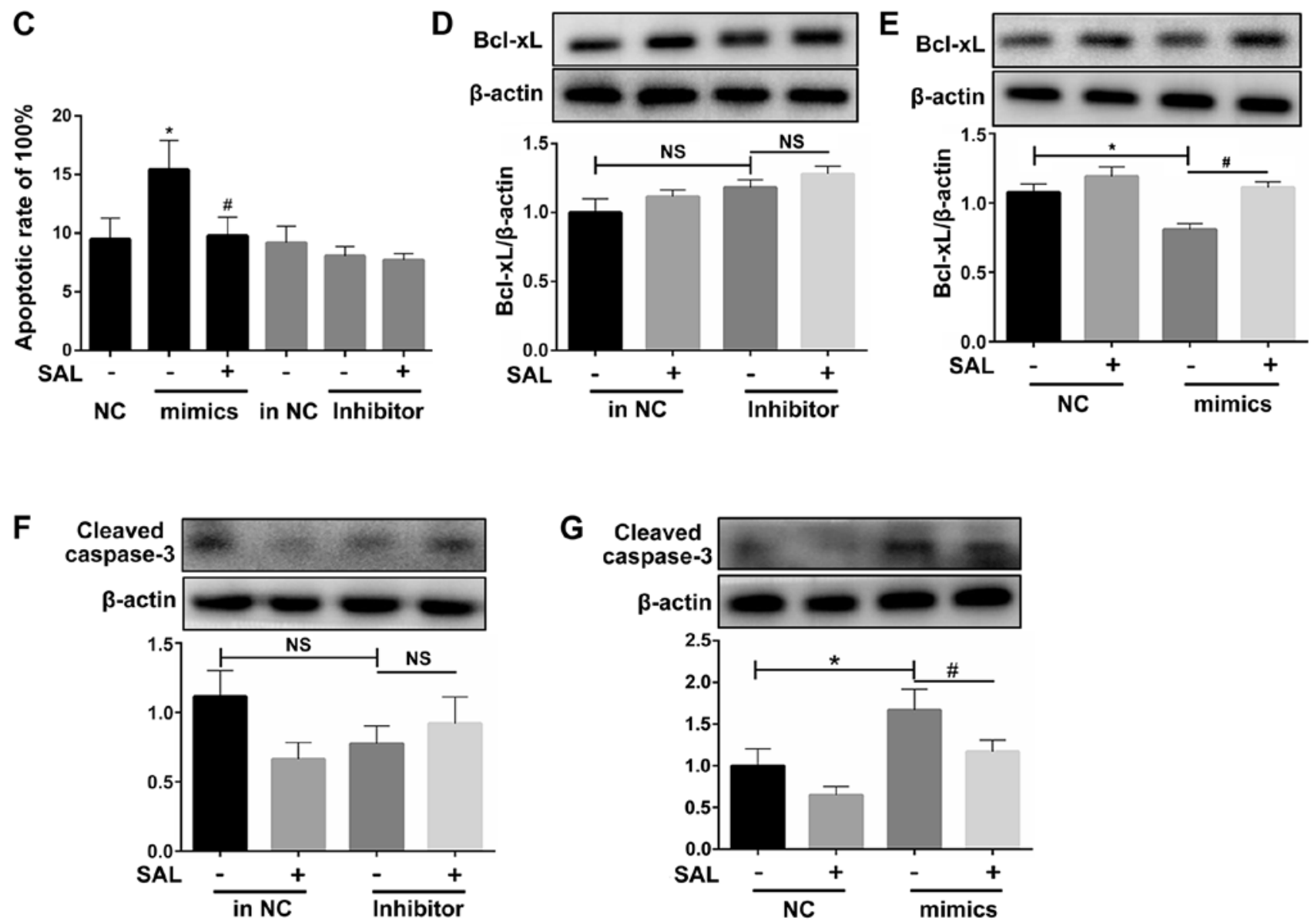

Figure 5. miR-133a participates in ox-LDL-induced apoptosis of HCAECs. (A) Confirmation of miR-133a overexpression or silencing following transfection with mimics or inhibitors in HCAECs by reverse transcription-quantitative polymerase chain reaction. (B and C) Flow cytometry at 48 h following transfection with miR-133a (mimics and inhibitor). (D and E) Expression of Bcl-xL at $48 \mathrm{~h}$ following transfection with miR-133a (mimics and inhibitor). ( $\mathrm{F}$ and $\mathrm{G})$ Expression of cleaved caspase- $348 \mathrm{~h}$ following transfection of miR-133a (mimics and inhibitor). ${ }^{*} \mathrm{P}<0.05,{ }^{* *} \mathrm{P}<0.01,{ }^{* * *} \mathrm{P}<0.001$ vs. negative control (NC) mimic or inhibitor; " $\mathrm{P}<0.05$ vs. treatment with salidroside (SAL) alone. -, without SAL treatment; +, $100 \mu \mathrm{M}$ SAL; NS, not significant; SAL, salidroside; ox-LDL, oxidized low-density lipoprotein; HCAECs, human coronary artery endothelial cells.

the concentration of ox-LDL and the duration of exposure. This result is consistent with the findings of $\mathrm{Xu}$ et al and Qin et al $(18,31)$.

Several miRNAs have been demonstrated to play a critical role in the pathogenesis of AS. For example, miRNA-181b has been shown to inhibit inflammatory injury in endothelial cells by regulating the $\mathrm{NF}-\kappa \mathrm{B}$ signal transduction pathway (32), whereas the effective blockage of the miR-92a pathway can prevent endothelial dysfunction and inflammation, thereby suppressing the development of AS (33). Furthermore, miR-126-5p can inhibit the expression of DIK1 to promote tissue repair and prevent the development of AS (34). In 

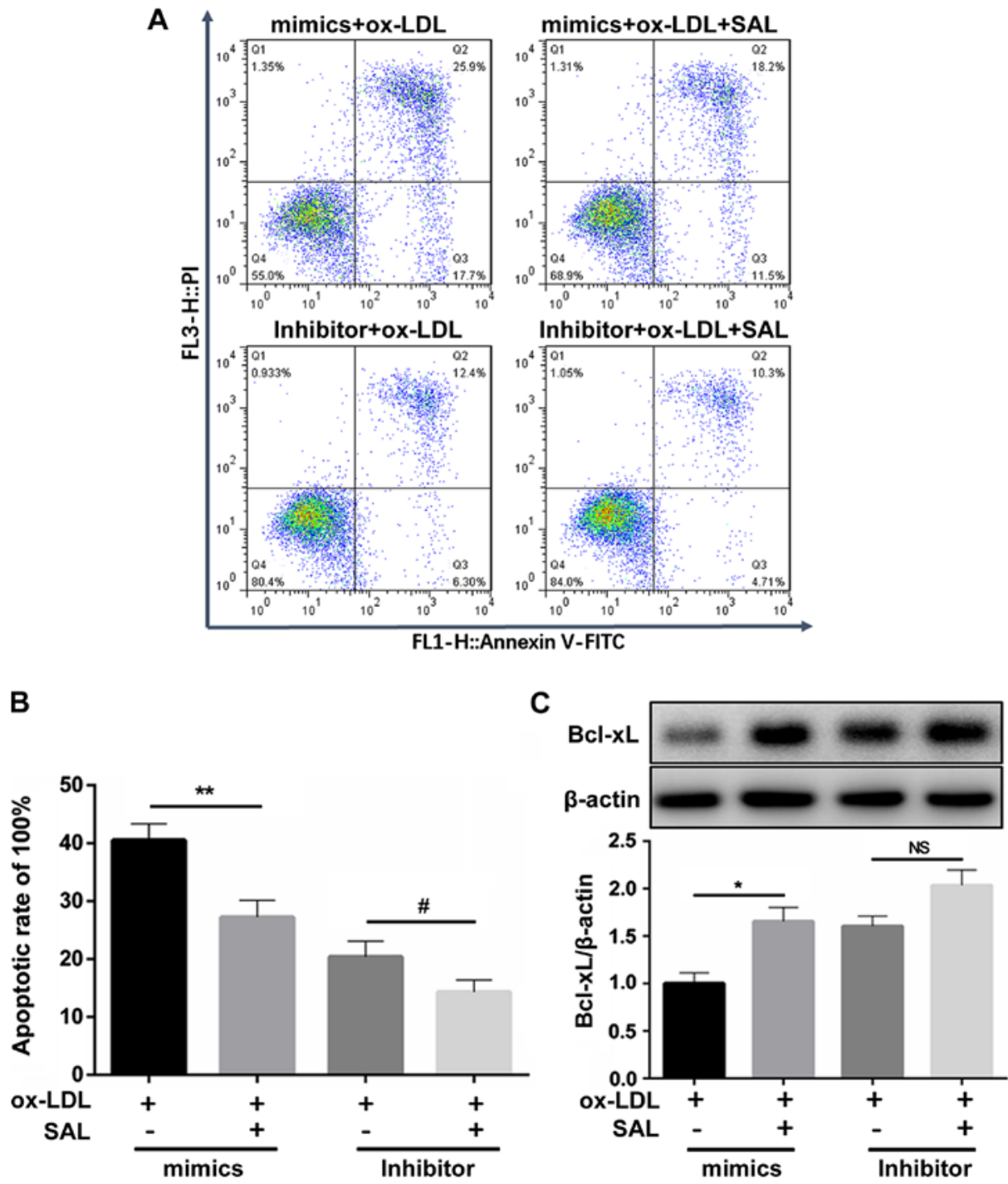

Figure 6. The apoptotic rate of cells overexpressing miR-133a increased and was reversed by SAL. The anti-apoptotic effect of SAL was attenuated following the knockdown miR-133a. (A and B) Results of flow cytometry of HCAECs exposed to ox-LDL with or without SAL for 24 h, at $48 \mathrm{~h}$ following transfection of miR-133a (mimics or inhibitor). (C) Expression of Bcl-xL in HCAECs exposed to ox-LDL with or without $\mathrm{SAL} 48 \mathrm{~h}$ after miR-133a transfection. * $<0.05$, ${ }^{* *} \mathrm{P}<0.01$, vs. ox-LDL; ${ }^{*} \mathrm{P}<0.05$ treatment with ox-LDL alone vs. treatment with ox-LDL + SAL. -, without SAL treatment; +, $100 \mu \mathrm{M}$ SAL + $75 \mu \mathrm{g} / \mathrm{ml}$ ox-LDL; NS, not significant; SAL, salidroside; ox-LDL, oxidized low-density lipoprotein; HCAECs, human coronary artery endothelial cells.

addition, the miR-26a-targeted regulation of TRPC6 has been found to prevent endothelial cell apoptosis (35). The present study demonstrated that miR-133a regulated the expression of $\mathrm{Bcl}-\mathrm{xL}$ and promoted endothelial cell apoptosis, providing a new understanding of a new pathway of endothelial cell apoptosis and a target for anti-apoptotic therapy.

Several reports have highlighted the effects of drugs on miRNA activity. For example, rapamycin has been reported to enhance the expression of miRNA-155 to promote autophagy and delay the formation of AS plaques (36). Similarly, Wujisan, a traditional Chinese medicine, has been found to regulate ICAM-1, VCAM-1 and E-selectin expression through miR10a and miR126-3p, thereby inhibiting the development of AS (37). However, to the best of our knowledge, no study available to date has examined whether or not SAL can regulate the activity of miRNAs in the context of AS. The present study found that SAL upregulated the protein expression of Bcl-xL, whereas it not affect the mRNA level of Bcl-xL. Therefore, it was hypothesized that there may be a non-coding RNA regulating the process of $\mathrm{Bcl}-\mathrm{xL}$ translation. Bioinformatics analysis was used to screen the miRNAs confirmed to target $\mathrm{Bcl}-\mathrm{xL}$ and regulate its expression. Among these, it was found that only the miR-133a levels were abnormally increased following ox-LDL-induced apoptosis.

The miR-133 family consists of 2 members, miR-133a and miR-133b, which are located on different chromosomes (38). Previous studies have found that miR-133a is a muscle-specific miRNA that plays an essential role in the normal development and function of the skeletal muscle and myocardium $(38,39)$. In addition, epithelial cell miR-133a expression has been reported to be upregulated by neurotensin, which mediates colitis (40). The present study found that miR-133a can regulate the transcript levels of the anti-apoptotic protein Bcl-xL, thereby highlighting its role in the process of endothelial cell apoptosis. Specifically, it was found that following the overexpression of miR-133a, the Bcl-xL protein levels significantly decreased, and the apoptotic rate increased in the HCAECs. Importantly, no significant differences in the expression of $\mathrm{Bcl}-\mathrm{xL}$ and apoptotic rates 
were observed following the silencing of miR-133a compared to those of the control group. Thus, Bcl-xL may not be regulated by endogenous miR-133a in the normal physiological state of endothelial cells, but rather only in a pathologic condition.

Rhodiola is recognized to be effective in the treatment of CHD, and SAL is its main active ingredient. Animal experiments have confirmed that SAL has a definite anti-AS effect $(41,42)$. Further mechanistic studies have demonstrated that SAL exerts antioxidant effects $(9,43)$, inhibits endoplasmic reticulum stress (44), exerts anti-inflammatory effects (45), inhibits foam cell formation (46) and exerts anti-proliferative effects on vascular smooth muscle (47). Accumulating studies have also indicated the role of SAL in endothelial cell apoptosis. SAL can upregulate the expression of the anti-apoptotic protein Bcl-2; downregulate the expression of the pro-apoptotic protein Bax; increase the content of ATP (45); inhibit the activation of caspase-3, caspase-9 and PARP (48); and activate AMPK to promote the PI3K/AKT signaling pathway, which in turn affects the expression of mammalian target of rapamycin (mTOR) (49). However, it is not clear whether SAL can regulate miR-133a and then affect the expression of the anti-apoptotic protein $\mathrm{Bcl}-\mathrm{xL}$ to protect the endothelium. The present study found that SAL impaired the ox-LDL-induced upregulated expression of miR-133a in HCAECs, thereby affecting the level of Bcl-xL. Significantly, the effect of SAL was decreased following the silencing of miR-133a, whereas the overexpression of miR-133a restored the effects of SAL treatment. Taken together, the results demonstrated that SAL inhibited the decrease in the expression of Bcl-xL via miR-133a, thereby preventing ox-LDL-induced endothelial cell apoptosis. Therefore, SAL preserves vascular function and confers protection against AS. However, the mechanisms through which SAL regulates miR-133a warrant further investigation, and animal experiments are required to confirm these effects in vivo.

In conclusion, the findings of the present study indicate that SAL inhibits the ox-LDL-induced upregulation of miR-133a expression, while promoting the expression of Bcl-xL, thereby preventing endothelial cell apoptosis. Therefore, it is suggested that SAL can preserve vascular function and prevent the development of AS.

\section{Acknowledgements}

Not applicable.

\section{Funding}

The present study was supported by the Foundation of Key Scientific Research Projects of Higher Education Institutions in Henan Province (grant nos. 18A320005 and 19A360032).

\section{Availability of data and materials}

All data generated or analyzed during the present study are included in this published article.

\section{Authors' contributions}

YoZ, FL and GZ conceived and designed the study. YoZ and FL performed the experiments with the assistance of ZY,
ZC, YC, and YiZ. ZY and YoZ analyzed the data. YoZ wrote the manuscript. All authors discussed the manuscript and all authors read and approved the final manuscript.

\section{Ethics approval and consent to participate}

Not applicable.

\section{Patient consent for publication}

Not applicable.

\section{Competing interests}

The authors declare that they have no competing interests.

\section{References}

1. Benjamin EJ, Virani SS, Callaway CW, Chamberlain AM, Chang AR, Cheng S, Chiuve SE, Cushman M, Delling FN, Deo R, et al: Heart disease and stroke statistics-2018 update: A report from the American heart association. Circulation 137: e67-e492, 2018.

2. Vita JA and Keaney JF Jr: Endothelial function: A barometer for cardiovascular risk? Circulation 106: 640-642, 2002.

3. Trpkovic A, Resanovic I, Stanimirovic J, Radak D, Mousa SA Cenic-Milosevic D, Jevremovic D and Isenovic ER: Oxidized low-density lipoprotein as a biomarker of cardiovascular diseases. Crit Rev Clin Lab Sci 52: 70-85, 2015.

4. Zhou F, Yang Y and Xing D: Bcl-2 and Bcl-xL play important roles in the crosstalk between autophagy and apoptosis. FEBS J 278: 403-413, 2011.

5. Menghini R, Stohr R and Federici M: MicroRNAs in vascular aging and atherosclerosis. Ageing Res Rev 17: 68-78, 2014.

6. Fichtlscherer S, De Rosa S, Fox H, Schwietz T, Fischer A, Liebetrau C, Weber M, Hamm CW, Röxe T, Müller-Ardogan M, et al: Circulating microRNAs in patients with coronary artery disease. Circ Res 107: 677-684, 2010.

7. Cipollone F, Felicioni L, Sarzani R, Ucchino S, Spigonardo F, Mandolini C, Malatesta S, Bucci M, Mammarella C, Santovito D, et al: A unique microRNA signature associated with plaque instability in humans. Stroke 42: 2556-2563, 2011.

8. Li P, Yin YL, Guo T, Sun XY, Ma H, Zhu ML, Zhao FR, Xu P, Chen Y, Wan GR, et al: Inhibition of aberrant MicroRNA-133a expression in endothelial cells by statin prevents endothelial dysfunction by targeting GTP cyclohydrolase 1 in vivo. Circulation 134: 1752-1765, 2016.

9. Xing SS, Yang XY, Zheng T, Li WJ, Wu D, Chi JY, Bian F, Bai XL, Wu GJ, Zhang YZ, et al: Salidroside improves endothelial function and alleviates atherosclerosis by activating a mitochondria-related AMPK/PI3K/Akt/eNOS pathway. Vascul Pharmacol 72: 141-152, 2015.

10. Panossian A, Hamm R, Wikman G and Efferth T: Mechanism of action of Rhodiola, salidroside, tyrosol and triandrin in isolated neuroglial cells: An interactive pathway analysis of the downstream effects using RNA microarray data. Phytomedicine 21 : 1325-1348, 2014.

11. Zhang YJ,Zhao GA, Lin F, et al: Research progress on anti-atherosclerotic mechanism of salidroside. Chin J Arteriosclerosis 6: 547-552, 2019 (In Chinese).

12. Tang Y, Vater C, Jacobi A, Liebers C, Zou X and Stiehler M: Salidroside exerts angiogenic and cytoprotective effects on human bone marrow-derived endothelial progenitor cells via Akt/mTOR/p70S6K and MAPK signalling pathways. Br J Pharmacol 171: 2440-2456, 2014.

13. Liu Y, Zhang X, Zhang Y, Hu Z, Yang D, Wang C, Guo M and Cai Q: Identification of miRNomes in human stomach and gastric carcinoma reveals miR-133b/a-3p as therapeutic target for gastric cancer. Cancer Lett 369: 58-66, 2015.

14. Ji F, Zhang H, Wang Y, Li M, Xu W, Kang Y, Wang Z, Wang Z, Cheng P, Tong D, et al: MicroRNA-133a, downregulated in osteosarcoma, suppresses proliferation and promotes apoptosis by targeting Bcl-xL and Mcl-1. Bone 56: 220-226, 2013. 
15. Ma J, Wang T, Guo R, Yang X, Yin J, Yu J, Xiang Q, Pan X, Zu X, Peng C, et al: MicroRNA133a and microRNA326 co-contribute to hepatocellular carcinoma 5-fluorouracil and cisplatin sensitivity by directly targeting B-cell lymphoma-extra large. Mol Med Rep 12: 6235-6240, 2015.

16. Livak KJ and Schmittgen TD: Analysis of relative gene expression data using real-time quantitative PCR and the 2(-Delta Delta C(T)) method. Methods 25: 402-408, 2001.

17. Qin B, Shu Y, Long L, Li H, Men X, Feng L, Yang H and Lu Z: MicroRNA-142-3p induces atherosclerosis-associated endothelial cell apoptosis by directly targeting rictor. Cell Physiol Biochem 47: 1589-1603, 2018.

18. Xu K, Liu P and Zhao Y: Upregulation of microRNA-876 induces endothelial cell apoptosis by suppressing $\mathrm{Bcl}-\mathrm{Xl}$ in development of atherosclerosis. Cell Physiol Biochem 42: 1540-1549, 2017.

19. Friedman RC, Farh KK, Burge CB and Bartel DP: Most mammalian mRNAs are conserved targets of microRNAs. Genome Res 19: 92-105, 2009.

20. Eulalio A, Huntzinger E and Izaurralde E: Getting to the root of miRNA-mediated gene silencing. Cell 132: 9-14, 2008.

21. Shimizu S, Takehara T, Hikita H, Kodama T, Miyagi T, Hosui A, Tatsumi T, Ishida $\mathrm{H}$, Noda $\mathrm{T}$, Nagano $\mathrm{H}$, et al: The let-7 family of microRNAs inhibits Bcl-xL expression and potentiates sorafenib-induced apoptosis in human hepatocellular carcinoma. J Hepatol 52: 698-704, 2010.

22. Guo R, Wang Y, Shi WY, Liu B, Hou SQ and Liu L: MicroRNA miR-491-5p targeting both TP53 and Bcl-XL induces cell apoptosis in SW1990 pancreatic cancer cells through mitochondria mediated pathway. Molecules 17: 14733-14747, 2012.

23. Yu S, Huang H, Deng G, Xie Z, Ye Y, Guo R, Cai X, Hong J, Qian D, Zhou X, et al: miR-326 targets antiapoptotic Bcl-xL and mediates apoptosis in human platelets. PLoS One 10: e0122784, 2015.

24. Zhang Y, Schiff D, Park D and Abounader R: MicroRNA-608 and microRNA-34a regulate chordoma malignancy by targeting EGFR, Bcl-xL and MET. PLoS One 9: e91546, 2014.

25. Choy JC, Granville DJ, Hunt DW and McManus BM: Endothelial cell apoptosis: Biochemical characteristics and potential implications for atherosclerosis. J Mol Cell Cardiol 33: 1673-1690, 2001

26. Kavurma MM, Bhindi R, Lowe HC, Chesterman C and Khachigian LM: Vessel wall apoptosis and atherosclerotic plaque instability. J Thromb Haemost 3: 465-472, 2005

27. Shamas-Din A, Kale J, Leber B and Andrews DW: Mechanisms of action of Bcl-2 family proteins. Cold Spring Harb Perspect Biol 5: a008714, 2013

28. Galluzzi L, Kepp O, Trojel-Hansen C and Kroemer G Mitochondrial control of cellular life, stress, and death. Circ Res 111: 1198-1207,2012.

29. Chen HC, Kanai M, Inoue-Yamauchi A, Tu HC, Huang Y, Ren D, Kim H, Takeda S, Reyna DE, Chan PM, et al: An interconnected hierarchical model of cell death regulation by the BCL-2 family. Nat Cell Biol 17: 1270-1281, 2015.

30. Fuchsluger TA, Jurkunas U, Kazlauskas A and Dana R: Anti-apoptotic gene therapy prolongs survival of corneal endothelial cells during storage. Gene Ther 18: 778-787, 2011.

31. Qin B, Xiao B, Liang D, Li Y, Jiang T and Yang H: MicroRNA let-7c inhibits Bcl-xl expression and regulates ox-LDL-induced endothelial apoptosis. BMB Rep 45: 464-469, 2012.

32. Sun X, He S, Wara AKM, Icli B, Shvartz E, Tesmenitsky Y, Belkin N, Li D, Blackwell TS, Sukhova GK, et al: Systemic delivery of microRNA-181b inhibits nuclear factor- $\mathrm{kB}$ activation, vascular inflammation, and atherosclerosis in apolipoprotein E-deficient mice. Circ Res 114: 32-40, 2014.

33. Loyer X, Potteaux S, Vion AC, Guérin CL, Boulkroun S, Rautou PE, Ramkhelawon B, Esposito B, Dalloz M, Paul JL, et al: Inhibition of microRNA-92a prevents endothelial dysfunction and atherosclerosis in mice. Circ Res 114: 434-443, 2014.
34. Schober A, Nazari-Jahantigh M, Wei Y, Bidzhekov K, Gremse F, Grommes J, Megens RT, Heyll K, Noels H, Hristov M, et al: MicroRNA-126-5p promotes endothelial proliferation and limits atherosclerosis by suppressing Dlk1. Nat Med 20: 368-376, 2014.

35. Zhang Y, Qin W, Zhang L, Wu X, Du N, Hu Y, Li X, Shen N, Xiao D, Zhang H, et al: MicroRNA-26a prevents endothelial cell apoptosis by directly targeting TRPC6 in the setting of atherosclerosis. Sci Rep 5: 9401, 2015.

36. Ma J, Yang S, Ma A, Pan X, Wang H, Li N, Liu S and Wu M: Expression of miRNA-155 in carotid atherosclerotic plaques of apolipoprotein $\mathrm{E}$ knockout $\left(\mathrm{ApoE}^{-{ }^{-}}\right)$mice and the interventional effect of rapamycin. Int Immunopharmacol 46: 70-74, 2017.

37. Han BH, Seo CS, Yoon JJ, Kim HY, Ahn YM, Eun SY, Hong MH, Lee JG, Shin HK, Lee HS, et al: The inhibitory effect of ojeoksan on early and advanced atherosclerosis. Nutrients 10: 1256, 2018.

38. $\mathrm{Yu} \mathrm{H}, \mathrm{Lu} \mathrm{Y}, \mathrm{Li} \mathrm{Z}$ and Wang Q: microRNA-133: Expression, function and therapeutic potential in muscle diseases and cancer. Curr Drug Targets 15: 817-828, 2014.

39. Chen JF, Mandel EM, Thomson JM, Wu Q, Callis TE, Hammond SM, Conlon FL and Wang DZ: The role of microRNA-1 and microRNA-133 in skeletal muscle proliferation and differentiation. Nat Genet 38: 228-233, 2006.

40. Law IK and Pothoulakis C: MicroRNA-133 $\alpha$ regulates neurotensin-associated colonic inflammation in colonic epithelial cells and experimental colitis. RNA Dis 2: e472, 2015

41. Zhang BC, Li WM, Guo R and Xu YW: Salidroside decreases atherosclerotic plaque formation in low-density lipoprotein receptor-deficient mice. Evid Based Complement Alternat Med 2012: 607508, 2012

42. Zhang LP: Effect of salidroside on atherosclerosis induced by intermittent hypobaric hypoxia in ApoE-/-mice. Chin J Arteriosclerosis 7: 675-679, 2014 (In Chinese).

43. Zhu Y, Zhang YJ, Liu WW, Shi AW and Gu N: Salidroside suppresses HUVECs cell injury induced by oxidative stress through activating the Nrf2 signaling pathway. Molecules 21: 1033,2016

44. Zhu L, Jia F, Wei J, Yu Y, Yu T, Wang Y, Sun J and Luo G: Salidroside protects against homocysteine-induced injury in human umbilical vein endothelial cells via the regulation of endoplasmic reticulum stress. Cardiovasc Ther 35: 33-39, 2017.

45. Liu L, Zhang S and Zhang MQ: Protective effect and mechanism of salidroside on endothelial cell surface injury induced by high glucose. Chin Herb Med 40: 949-952, 2017 (In Chinese).

46. Ni J, Li Y, Li W and Guo R: Salidroside protects against foam cell formation and apoptosis, possibly via the MAPK and AKT signaling pathways. Lipids Health Dis 16: 198, 2017.

47. Zhuang X, Maimaitijiang A, Li Y, Shi H and Jiang X: Salidroside inhibits high-glucose induced proliferation of vascular smooth muscle cells via inhibiting mitochondrial fission and oxidative stress. Exp Ther Med 14: 515-524, 2017.

48. Zhao X, Jin L, Shen N, Xu B, Zhang W, Zhu H and Luo Z: Salidroside inhibits endogenous hydrogen peroxide induced cytotoxicity of endothelial cells. Biol Pharm Bull 36: 1773-1778, 2013.

49. Xu MC, Shi HM, Wang H and Gao XF: Salidroside protects against hydrogen peroxide-induced injury in HUVECs via the regulation of REDD1 and mTOR activation. Mol Med Rep 8: 147-153, 2013.

This work is licensed under a Creative Common Attribution-NonCommercial-NoDerivatives 4.0 International (CC BY-NC-ND 4.0) License. 